\title{
Investigation of Surface Roughness and Chip Forms in Milling of Stainless Steel by MQL Method
}

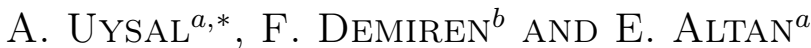

${ }^{a}$ Yildiz Technical University, Department of Mechanical Engineering, 34349 Istanbul, Turkey

${ }^{b}$ Yildiz Technical University, Graduate School of Natural and Applied Sciences, 34349 Istanbul, Turkey

Stainless steel materials have been used in many fields such as automotive, food, medical, chemistry etc. by applying machining operations although they are categorized under a group of materials whose machinability is difficult due to high strength, low thermal conductivity and work hardening tendency during machining. It is possible that these materials can be machined by using various cutting fluids, but cutting fluids have disadvantages such as being harmful to the environment and health. In this study, it is intended that the minimum quantity lubrication method is applied by using commercial vegetarian cutting fluid and uncoated and TiN coated WC cutting tools during milling of AISI 304 (austenitic stainless steel) and AISI 420 (martensitic stainless steel) materials and the sustainable machining is realized. Milling operations will be repeated even by applying the dry machining for the purpose of being able to compare the results obtained from minimum quantity lubrication method. The workpiece surface roughness and chip forms were investigated.
\end{abstract}

DOI: 10.12693/APhysPolA.129.439

PACS/topics: 81.05.- -t

\section{Introduction}

Stainless steel materials have been classified as hardto-cut materials owing to their hardening tendency and low thermal conductivity. However, they are commonly used in many fields and the studies on machining of them have been carried out. Lin $[1,2]$ investigated the reliability and failure of face-milling tools in milling of stainless steels. Nordin et al. [3] studied the performance of multilayered and single-layered coatings in milling of stainless steels. Liew and Ding [4] examined the titanium aluminum nitride (TiAlN) coated and uncoated tungsten carbide (WC) cutting tools in milling of modified AISI 420 martensitic stainless steel at low cutting speeds. It was found that the coating increased the abrasive resistance of the cutting tool. Additionally, in many researches, it has been specified that the minimum quantity lubrication (MQL) method has many advantages when compared to dry and flood cuttings. In MQL method, the pulverized cutting fluid penetrates in the cutting zone and provides the cooling, lubricating, and removing the chips [5]. MQL method minimizes the environmental impact by significantly reducing fluid usage and eliminating the need for coolant treatment and disposal. In literature, it was specified that the MQL cutting could be an alternative to flood cooling [6, 7]. Liao et al. [8] analyzed the MQL cutting in high speed milling and researchers indicated that the MQL method increased the cutting tool life and the surface finish. Fratila and Caizar [9] and Shahrom et al. [10] presented that the MQL method gave better surface roughness than dry and flood cuttings. In many researches, the MQL method has been

\footnotetext{
*corresponding author; e-mail: auysal@yildiz.edu.tr
}

investigated and its performance has been evaluated. For this reason, in this study, the surface roughness and the chip forms were investigated during MQL milling of AISI 304 austenitic stainless steel and AISI 420 martensitic stainless steel with uncoated and titanium nitride (TiN) coated WC cutting tools. In MQL milling, a commercial vegetable cutting fluid was used and the experiments were also performed in dry condition.

\section{Materials and equipments}

Experiments were conducted on First MCV-300 CNC machining center by using uncoated and TiN coated WC inserts. The $\mathrm{WC}$ inserts were coated by physical vapor deposition (PVD) method and the chemical compositions of the coating were $52 \% \mathrm{Ti}$ and $48 \% \mathrm{~N}$. The inserts was mounted on a $32 \mathrm{~mm}$ diameter end mill. In this study, AISI 304 austenitic stainless steel and AISI 420 martensitic stainless steel were chosen as workpiece materials and their chemical compositions are given in Table I. The stainless steel specimens were prepared in dimensions of $400 \times 250 \times 6 \mathrm{~mm}$.

TABLE I

Chemical compositions of AISI 304 austenitic and AISI 420 martensitic stainless steels.

\begin{tabular}{c|c|c|c|c|c|c|c}
\hline \hline $\mathrm{C} \%$ & $\mathrm{Si} \%$ & $\mathrm{Mn} \%$ & $\mathrm{P} \%$ & $\mathrm{~S} \%$ & $\mathrm{Cr} \%$ & $\mathrm{Ni} \%$ & $\mathrm{~N} \%$ \\
\hline \multicolumn{7}{c}{ AISI 304 austenitic stainless steel } \\
\hline 0.023 & 0.49 & 1.51 & 0.027 & 0.003 & 18.1 & 8.1 & 0.054 \\
\hline AISI & 420 martensitic stainless steel \\
\hline 0.36 & 0.42 & 0.37 & 0.022 & 0.003 & 13.11 &
\end{tabular}

The milling operations were carried out under dry and MQL conditions. In MQL milling, Werte DKN 25 micro lubrication system was used and Eraoil KT/2000 was used as vegetable cutting fluid. Cutting parameters can 
be seen in Table II. Surface roughnesses $\left(R_{\mathrm{a}}\right)$ of milled slots were measured by Time TR200 surface roughness tester. Five measurements were performed on each surface and arithmetic means were calculated. The chip forms were examined by SOIF XLB45-B3 digital stereo microscope.

TABLE II

Cutting parameters.

\begin{tabular}{c|c|c|c|c|c}
\hline \hline $\begin{array}{c}\text { Milling } \\
\text { conditions }\end{array}$ & $\begin{array}{c}\text { MQL flow } \\
\text { rate } \\
{[\mathrm{ml} / \mathrm{h}]}\end{array}$ & $\begin{array}{c}\text { MQL } \\
\text { pressure } \\
\text { [bar] }\end{array}$ & $\begin{array}{c}\text { Spindle } \\
\text { speed } \\
{[\mathrm{rpm}]}\end{array}$ & $\begin{array}{c}\text { Feed } \\
\text { rate } \\
{[\mathrm{mm} / \mathrm{min}]}\end{array}$ & $\begin{array}{c}\text { Depth } \\
\text { of cut } \\
{[\mathrm{mm}]}\end{array}$ \\
\hline $\begin{array}{c}\text { Dry } \\
\text { and MQL }\end{array}$ & 20 & 5 & 995 & 180 & 0.5
\end{tabular}

\section{Results and discussion}

In milling of AISI 304 austenitic and AISI 420 martensitic stainless steels, the maximum surface roughness was measured during dry cutting as seen in Fig. 1a and b. The TiN coated WC cutting tools caused a decrease in the surface roughness due to the fact that the TiN coating reduces the friction and the cutting temperatures and so less surface roughness was obtained. In MQL cutting, the pulverized cutting fluid is sent to the interface between workpiece and cutting tool. Therefore, the surface roughness decreased in the result of the effective lubrication and cooling of the MQL method as presented in literature [11-14]. When compared to austenitic and martensitic stainless steels in terms of the surface roughness, lower surface roughness was obtained in the milling of martensitic stainless steel owing to fact that its structure is more brittle than that of the austenitic stainless steel. In addition, the austenitic stainless steel sticks to the cutting tool during the milling operation and so the surface roughness increased. The least surface roughness was obtained in MQL milling of the martensitic stainless steel with the TiN coated WC cutting tool.

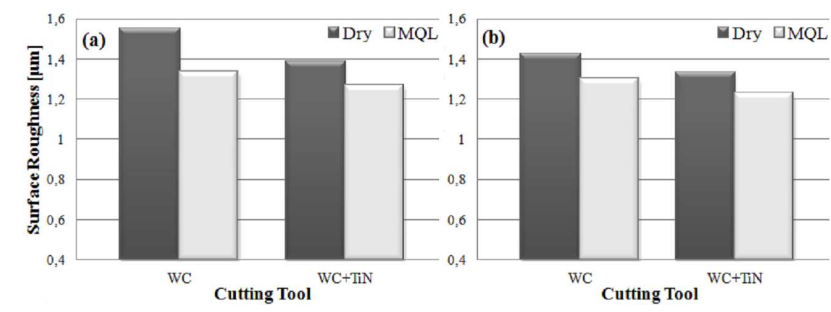

Fig. 1. Surface roughness: (a) AISI 304, (b) AISI 420.

The chip forms are given in Fig. 2 and Fig. 3. In dry cutting, more deformed, continuous, and undesired chips were observed for both stainless steels due to occurring high cutting temperature as seen in Fig. 2a,b and Fig. 3a,b. The TiN coating made the chips more acceptable than that formed in milling with the uncoated WC cutting tool due to increase of the cutting facilitation

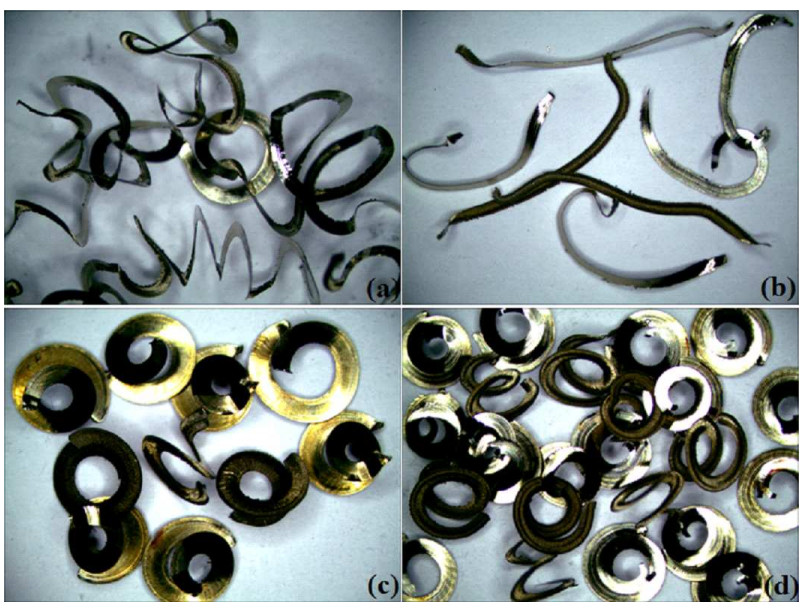

Fig. 2. Chip forms in machining of AISI 304 austenitic stainless steel: (a) dry cutting with WC, (b) dry cutting with TiN coated WC, (c) MQL cutting with WC, (d) MQL cutting with TiN coated WC.

(Fig. 2b and Fig. 3b. In MQL milling, it is known that the cutting fluid is sent with pressure air and this may cause the chip breaking and so more regular chips occur than that occurs in dry cutting. As seen in Fig. 2c,d and Fig. 3c,d, spiral chips were formed as a result of MQL effect. In addition, more scrolled or elongated chips were formed in milling of AISI 304 austenitic stainless steel than observed in milling of AISI 420 martensitic stainless steel due to the ductile structure of AISI 304.

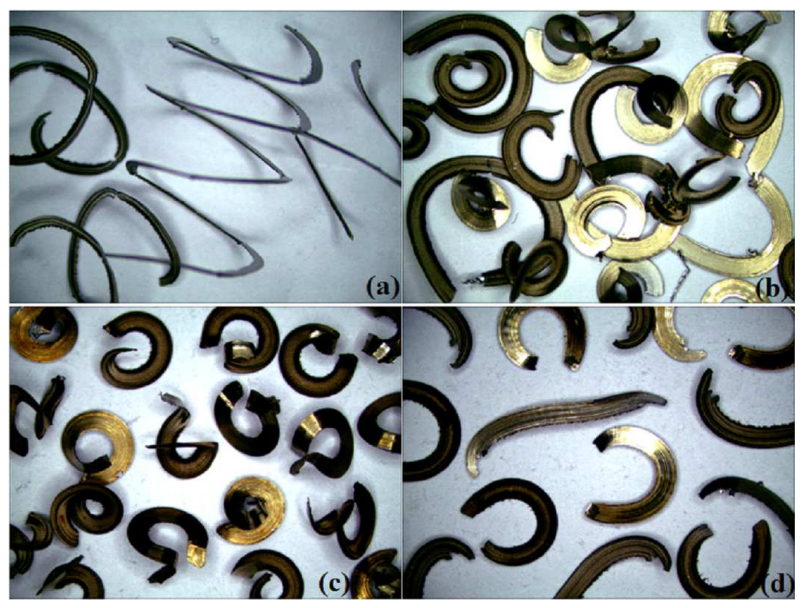

Fig. 3. As in Fig. 2 but for AISI 420 martensitic stainless.

\section{Conclusion}

In this study, milling of AISI 304 austenitic and AISI 420 martensitic stainless steels was investigated and the effects of TiN coating, dry cutting, and MQL cutting on the surface roughness and chip forms were examined. The maximum surface roughness was observed in dry cutting for both stainless steels. The surface roughness could be reduced by using TiN coating. However, the minimum surface roughness was measured in MQL milling. 
In additions, AISI 420 martensitic stainless steel gave better surface roughness results than AISI 304 austenitic stainless steel. When investigated the chip forms, more deformed and irregular chip forms were observed in dry cutting. The TiN coating and MQL method made the chips more regular and acceptable for both materials. But, it was observed that the chips of AISI 304 austenitic stainless steel were more scrolled or elongated than that of AISI 420 martensitic stainless steel.

\section{Acknowledgments}

This research has been supported by the Scientific and Technological Research Council of Turkey (TÜBİTAK), project No. 114M098.

\section{References}

[1] T.R. Lin, J. Mater. Process. Tech. 79, 41 (1998).

[2] T.R. Lin, J. Mater. Process. Tech. 108, 12 (2000).

[3] M. Nordin, R. Sundström, T.I. Selinder, S. Hogmark, Surf. Coat. Technol. 133-134, 240 (2000).
[4] W.Y.H. Liew, X. Ding, Wear 265, 155 (2008).

[5] L.N.L. de Lacelle, C. Angulo, A. Lamikiz, J.A. Sánchez, J. Mater. Process. Tech. 172 11 (2006).

[6] M. Rahman, A.S. Kumar, M.U. Salam, Int. J. Mach. Tool. Manuf. 42, 539 (2002).

[7] H.A. Kishawy, M. Dumitrescu, E.G. Ng, M.A. Elbestawi, Int. J. Mach. Tool. Manuf. 45, 219 (2005).

[8] Y.S. Liao, H.M. Lin, Y.C. Chen, Int. J. Mach. Tool. Manuf. 47, 1667 (2007).

[9] D. Fratila, C. Caizar, J. Clean. Prod. 19, 640 (2011).

[10] M.S. Shahrom, N.M. Yahya, A.R. Yusoff, Proc. Eng. 53, 594 (2013)

[11] M.M.A. Khan, M.A.H. Mithu, N.R. Dhar, J. Mater. Process. Tech. 209, 5573 (2009).

[12] T. Thepsonthi, M. Hamdi, K. Mitsui, Int. J. Mach. Tool. Manuf. 49, 156 (2009).

[13] M. Hadad, B. Sadeghi, J. Clean. Prod. 54, 332 (2013).

[14] J. Sharma, B.S. Sidhu, J. Clean. Prod. 66, 619 (2014). 